International Journal of Social Sciences and Humanities
Available online at http://sciencescholar.us/journal/index.php/ijssh
Vol. 3 No. 2, August 2019, pages: 238 245
e-ISSN: 2550-7001, p-ISSN: 2550-701X
https://doi.org/10.29332/ijssh.v3n2.322

\title{
The Importance of Formative Assessment in the Learning Teaching Process
}

\author{
CrossMark

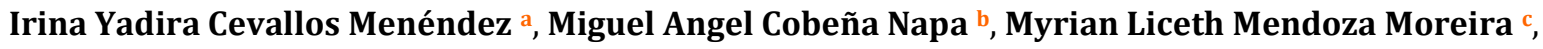 \\ Gema Gabriela Vélez Zambrano ${ }^{\mathrm{d}}$
}

Article history: Received 27 December 2018, Accepted: 30 April 2019, Published: 27 August 2019

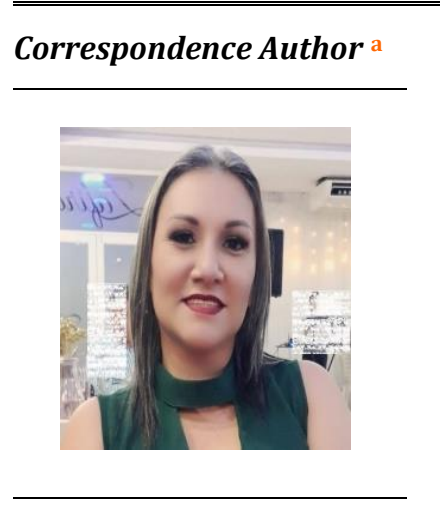

Keywords

enseñanza-learning;

formative evaluation;

learning;

outcomes;

student performance;

\begin{abstract}
The present research aimed to know the role that the formative evaluation fulfills in the teaching-learning process, this is based on a continuous evaluation process that occurs during learning, based on the search and interpretation of evidence about student performance and the scope of students' different goals, projections or objectives. Within the methodology, analytical and research methods were used, thus knowing the importance of evaluation; analyzing the needs and interests of students through a survey that was conducted in the Technical Educational Unit "Walter Francisco Andrade Ortiz" of the City of Pedernales; with the aim of raising awareness in the teachers of the institution, the importance of formative evaluation as a means to raise the quality of performance of students, and thus to demonstrate the results of learning obtained within the classroom in students: The results of the research showed that the formative assessment improves the school performance of the students and this can be used as a strategy to promote collaboration between them.
\end{abstract}

e-ISSN: 2550-7001, p-ISSN: 2550-701X ๑ Copyright 2019. The Author. SS Journals Published by Universidad Técnica de Manabí. This is an open-access article under the CC BY-SA 4.0 license (https://creativecommons.org/licenses/by-sa/4.0/) All rights reserved.

\section{Contents}

Abstract

1. Introduction .

2. Materials and Methods.

3. Results and Discussions

4. Conclusion

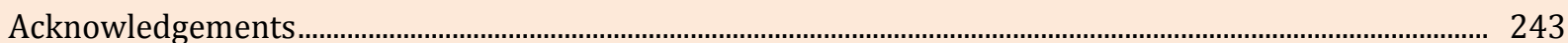

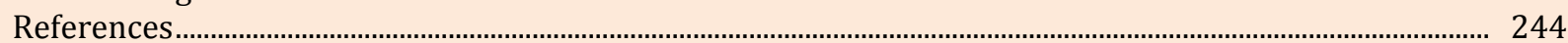

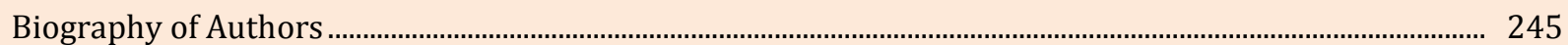

a Pontifical Catholic University of Ecuador, Quito, Ecuador

b Pontifical Catholic University of Ecuador, Quito, Ecuador

c Pontifical Catholic University of Ecuador, Quito, Ecuador

d Unit Technical Educational Pedernales, Pedernales, Ecuador 


\section{Introduction}

Evaluation is a dynamic, daily and practical process that is used in the educational field to know what are the priority needs that should be addressed. It is an everyday work in the classroom, and is used at all times to guide the teaching process - learning, a process that must be carried out continuously and personalized, inducing the teacher to demonstrate the intra-classroom learning acquired by his students to improve the educational quality at the Institution (Mora, 2004; Macías et al., 2018; Mahendra, 2016).

For learning to be effective, training is needed for the formative assessment provided to the student in a continuous and consistent way, applied theoretically or practically to recognize the difficulties of a topic dealt with, the knowledge gained and the successes of the Students. This type of evaluation focuses on the correct learning of students, correcting teaching practice and implementing appropriate strategies, methodologies and resources in the classroom (Talanquer, 2015).

The purpose of this research was to understand the importance of the formative evaluation in the teaching process learning in the Educational Unit "Walter Francisco Andrade Ortiz"; institution that is located in the City of Pedernales and, in this way, be able to determine the qualitative and quantitative criteria that allow forging the best path to a successful level of learning achievement, always aiming at the development interdisciplinary of the evaluated file.

When talking about studies, it is impossible not to resort to the reflective analysis of the various postures, authors, specific cases and their characteristics; all with the intention of recognizing the theoretical marrow of the importance of formative evaluation and thus contributing to the improvement of the methodologies, strategies or teaching procedures used daily by teachers in their practices andro-pedagogical, encouraging the development of different types of skills in students and enhancing their knowledge for meaningful learning.

A teacher who applies the formative assessment all the time in the classroom, will demonstrate the strengths, talented weaknesses and qualities that his students have, promote values such as respect, solidarity and responsibility and allow him to modify his teaching and evaluation practices turning the classroom into a classroom where the collaboration and participation of students in activities are groups as individual, generating in them feelings of pride, satisfaction and the scope of their objectives, goals and desired projections.

The formative evaluation as a critical activity of learning involves assuming another conception of knowledge and learning, otherwise there is strong resistance to loss of control and the fear of not being strictly objectives.

The way students are evaluated is very limited and $80 \%$ focus on exams, writings and reports of some kind; this makes them restrictive methods that do not allow them to demonstrate all their competencies and skills, students Martin (2007), demonstrate the benefits of an innovative assessment, where they contemplate other forms other than written examination as they are oral presentations, group work, self-assessment, and co-evaluation, but when that evaluation is conjunctive with such students, and they have a clear idea of what the whole process is going to be like, it is composed of tasks relevant and meaningful to their and allow them to apply and develop their knowledge and skills.

Currently, results about the quantity and quality of student performance are being evaluated by measuring Zubieta (2017; Iriani et al., 2018; Suryasa et al., 2017), performance, these performance-based assessments require students to demonstrate 10 , putting in place a particular procedure comprising an appropriate method for recording such performances and a set of criteria to be taken into account in the formative assessment.

\section{Materials and Methods}

This research was exploratory in type and analytical, critical and scientific methods were used, applying the survey as a technique. It was considered as a population 150 students of the Educational Unit "Walter Francisco Andrade Ortiz", from which 25 students from different basic years were taken as a sample. This

Menéndez, I. Y. C., Napa, M. A. C., Moreira, M. L. M., \& Zambrano, G. G. V. (2019). The importance of formative assessment in the learning teaching process. International Journal of Social Sciences and Humanities, 3(2), 238249. https://doi.org/10.29332/ijssh.v3n2.322 
information was processed and presented using statistical tables, which were analyzed with different scientific positions, the equation was used (Larry, 2009).

\section{Results and Discussions}

Throughout his life the human being acquires new knowledge, as well as skills and attitudes that allow him to evolve in all facets of his existence, including how he manages educational processes, this according to the development of the interpersonal relationships between the different actors in society. The evaluation plays a fundamental role in the search and satisfaction of the interests of the different participants of the teachinglearning process, being able to generate new alternatives and tools necessary for the achievements, objectives, Goals.

It is a process that consists in obtaining, identifying, and providing relevant information from students, assessing their different opinions, argumentations and creating a student-teacher link to the achievement of their goals and objectives along with the study of resources and activities necessary for the training of the person, the monitoring of their achievements and the implementation of the results and their impact, therefore the purpose of the evaluation is to demonstrate the teaching-learning of the students leading the teacher to know the results obtained in this process. (Mora, 2004).

An appropriate evaluation is carried out from the beginning to the final part of the class, i.e. in a systematic and organized manner in which the teacher shows the learning acquired by the students in the classroom, if the result of the evaluation by part (e) of the student is unfavorable, the teacher will develop a new plan that will allow him to obtain accurate results and know the lack of a lack that the student has in terms of his learning. The best way to evaluate a student is both theoretically and practically and the results are then key inputs to make decisions, set responsibilities, set goals, define criteria and determine concrete actions that improve the student learning. The evaluation is a somewhat complex but unavoidable process, a positive action that the teacher performs to know and identify the strengths of the student's student (before, during and after the educational experience), and thus execute Stufflebeam \& Shinkfield (2015), concrete actions in order to correct or improve their action within the process.

When evaluating the learnings that students have made, we are also evaluating, whether they want or not, the teaching that we have carried out in the classroom.- The evaluation is never, in a rigorous sense, of teaching or learning, but rather of the pro teaching-learning baskets implemented in the education system.

In the teaching-learning process within the classroom the evaluation seeks to be part of the scheme and organizational structure of the different activities, work or workshops provided in it as an effective and informative knowledge tool or data that revalue the knowledge obtained by students implementing the appropriate didactics for constant and participatory evaluation, the evaluation has always been within our daily life, being an indicator of progress in the teaching-learning, allowing to know the development of the knowledge acquired by the student throughout their school year (Lopez, 2005).

The different collective and participatory activities of students implemented in class make the evaluation an instrument of analysis, monitoring, and improvement of learning in students because the role of the teacher in the process of teaching and its implementation in the classroom are determining factors. , an appropriate evaluation brings with it various phases that will allow the teacher to obtain the desired results by showing the learning in the students (Acuna \& Ramirez, 2010).

Learning that is given through knowledge is theoretically as a practical by issuing a value judgment about an activity that is to be evaluated to generate meaningful learning in students in order to improve the quality of the entire process of Learning (Davies \& LeMahieu, 2003).

Formative assessment is necessary for the learning processes of students, its application is continuous throughout the school year, allowing the teacher to know and highlight the different achievements, successes, weaknesses, and shortcomings of the students in a subject Treaty

The proper and effective use of formative assessment supports learning, support provided by teachers by drawing up the different assessments according to the need of one or another student to demonstrate the acquired learning, you can evidence that proposing a challenge where assessment is concerned is to ensure healthy practices effectively so that students benefit (Stiggins, 2007). 
They are designed by teachers to demonstrate and monitor the learning process, most of these assessments are authentic for all kinds of assessments that are carried out with the aim of teaching students the tasks through which they are evaluated, requisitioned students to complete real or pedagogical activities to demonstrate their knowledge and skills (McMillan, Classroom Evaluation, 2001).

The formative assessment is based on the analysis of evidence collected by teachers that allow them to make comments and implement actions to improve the understanding of students, this type of evaluation involves a process in which teachers do students' thinking, make inferences about the level of understanding achieved and act on the information available in order to achieve established learning goals, (Furtak, 2012), it implies a challenge for the teacher, demand knowledge in the discipline, constant attention to the ideas expressed by students, recognition of the most common learning difficulties and familiarity with teaching strategies that respond to the diverse needs of students. The essence off-normative evaluation is informed action (Martinez, 2013).

We must go in search of the meaning and implications of formative evaluation and curriculum change that evaluates innovation entails, in order for this change to be possible the pedagogical meaning of the evaluation concept must be incorporated by considering what it is to value and this, depending on the conceptualization of the evaluation that we each have, will develop the teaching practices and determine the purposes that we give for the students, because let us not forget that the evaluation conditions the learning and that the practices pointing out ways to learn in students (Canabal \& Castro, 2012).

These evaluation practices, generated from the conceptions of the teachers, derive in some contradictions present in many of the evaluation processes developed in the classroom. These include understanding assessment as a measurement rather than a learning opportunity, focusing it on repetitive learning rather than comprehensive learning, understanding continuous assessment as fragmentation, worrying about objectivity rather than taking care of non-arbitrariness, restricting the possibility of student participation or focusing the debate on instruments rather than the purposes of evaluation, all of which takes us away from the path to a genuine assessment Formative. (Canabal, 2011).

Two basic needs to which the evaluation should respond should be distinguished: the first, evaluation as an understanding of the learning process in the group in which the primary purpose is to promote reflection and participation in the analysis, and the second, the accreditation, which relates to the institutional requirement to certify if the knowledge that is marked in the objectives is obtained, has been positioned as a useful tool for the improvement of educational quality, as it provides information that establishes strengths and weaknesses that guide the design of improvement plans by education actors. It is also an important source for educational research and innovations so that the quality of education is reflected in the results obtained, starting from the teaching-learning process, using transformations that will provide the goal to be achieved (Horbath \& Gracia, 2014).

Training assessment tools should be developed according to the type of teaching of the student and incorporate methodologies, resources and teaching activities that serve to enhance meaningful student learning, focuses on develop cycles of action and research and training in such a way that teachers are able to incorporate the most relevant methodologies into the teaching and learning process, both individually and collectively with a commitment to developing experiences of formative and shared evaluation in each of the subjects they teach (Lopéz et al., 2008).

This requires that the assessment be used to feed students back on how they go in that process and it is important that teachers promote an enabling environment within the classroom for assessments to facilitate learning.

The feedback provided to the student helps the teacher take concrete and corrective actions to improve their teaching performance, aimed at their perfection, this feedback can incentivize motivation and learning and is implemented according to the different needs of students (McMillan, 2007).

The formative evaluation should be a triangulated, multidimensional evaluation, which allows obtaining information on the learning and evolution of students from different perspectives for the scope of their goals, purposes, and projections.

To get the size of the sample to be cuetar, theec uation was used (Larry, 2009), as seen in equation (1).

\footnotetext{
Menéndez, I. Y. C., Napa, M. A. C., Moreira, M. L. M., \& Zambrano, G. G. V. (2019). The importance of formative assessment in the learning teaching process. International Journal of Social Sciences and Humanities, 3(2), 238249. https://doi.org/10.29332/ijssh.v3n2.322
} 


$$
n=\frac{z^{2} \cdot \mathrm{p} \cdot \mathrm{q} \cdot \mathrm{N}}{N \cdot e^{2}+z^{2} \cdot p \cdot q}
$$

Where:

$\mathrm{n}^{\prime}$ : sample size No. Total, of the population

$z^{2}$ : Confidence level (1.96)

$\mathrm{p}$ : Probability of success, or expected proportion (0.5)

$\mathrm{q}$ : Probability of failure (0.5)

$e^{2}$ : Acceptable sample error limit (0.05)

The research is whether the formative assessment brings positive results, resulting in what is observed in Figure (1), that $80 \%$ of students agree, with the application of this method.

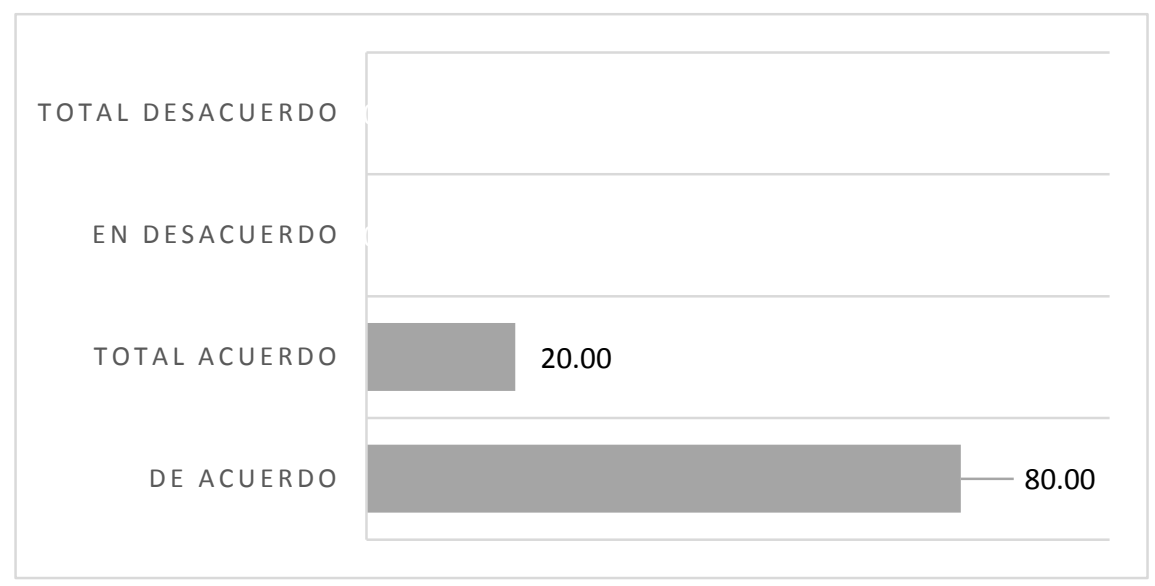

Figure 1. Application of formative assessment

It was investigated whether the formative assessment is a strategy that promotes collaboration among students, resulting in what is observed in Figure (2), that $100 \%$ of students are in complete agreement, that the application of this method is essential to promote collaboration with each other.

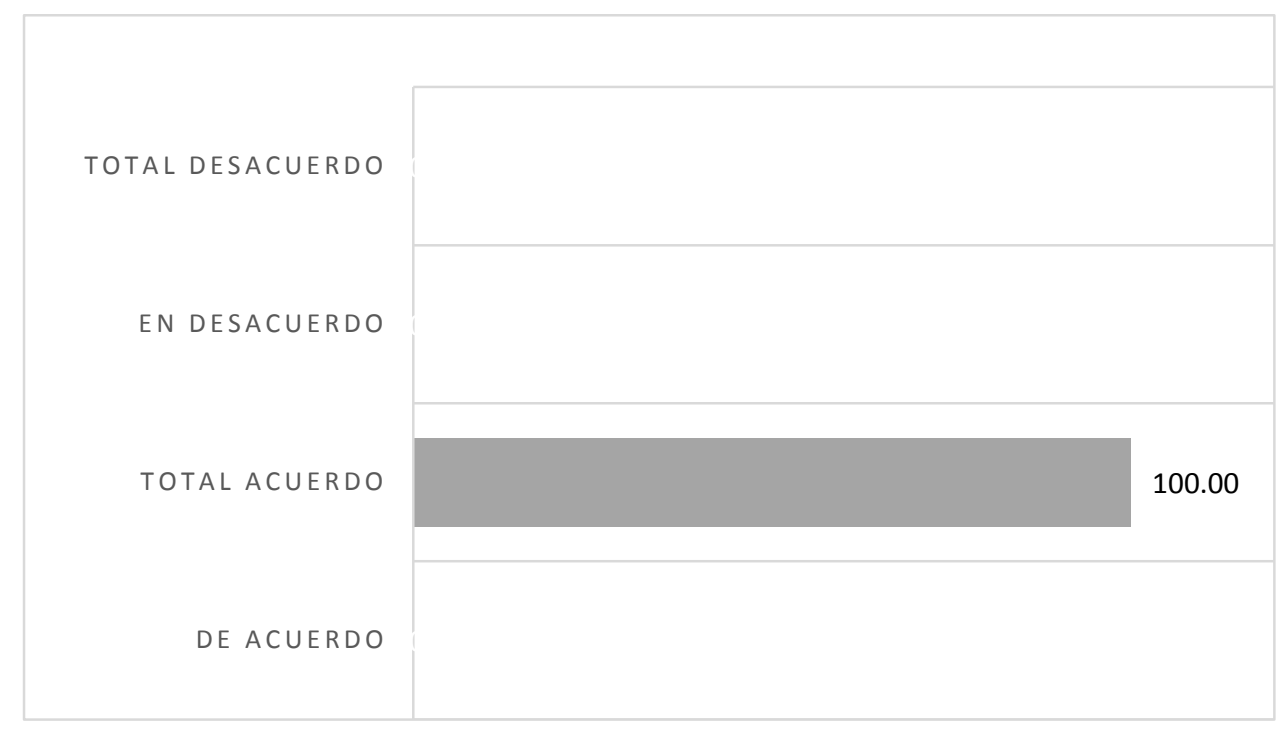

Figure 2. Collaboration among students 


\section{Conclusion}

Based on our research, it can be concluded that:

Formative assessment is applied before, during, and after class; and, it must continue to be treated as a fundamental process within the learning process, the same one that improves the school performance of the evaluated body to develop its cognitive, linguistic, intra, and interpersonal skills enhancing the scope of their goals, goals, and goals.

EU teachers. "Walter Andrade Ortiz", daily they strengthen the student-teacher relationship, improves the level of learning by implementing the formative assessment by applying the necessary feedback.

Educational assessment is a fundamental part of curriculum design, along with resources, didactics and methodological strategies; to promote collaboration among students and thus strengthen the teachinglearning process.

\section{Acknowledgments}

Ouren during thanks to the Pontifical Catholic University, the Manabí headquarters for the high-level teaching that is provided by the different Professors in each of the subjects; to the master's degree Innovation in Education that in its curriculum allows us to develop and achieve our desired objectives and projections. To Dr. María Rodríguez Gámez, professor of the Postgraduate For her teaching, dedication, and compression throughout the learning time. To the Walter Zambrano Ortiz Educational Institution for providing us with the required information.

Menéndez, I. Y. C., Napa, M. A. C., Moreira, M. L. M., \& Zambrano, G. G. V. (2019). The importance of formative assessment in the learning teaching process. International Journal of Social Sciences and Humanities, 3(2), 238- 


\section{References}

Acuna, M., \& Ramírez, L. (2010). Telesecondary evaluation process test. Ra Ximhai, 6(3), 421-443.

Canabal García, C., \& Castro Martín, B. (2012). La evaluación formativa:¿ La utopía de la Educación Superior?.

Canabal, C. (2011). Paradoxes and dilemmas in the assessment of competition.Madrid: Dykinson.

Davies, A., \& LeMahieu, P. (2003). Assessment for learning: Reconsidering portfolios and research evidence. In Optimising new modes of assessment: In search of qualities and standards (pp. 141-169). Springer, Dordrecht.

Furtak, E. M. (2012). Linking a learning progression for natural selection to teachers' enactment of formative assessment. Journal of Research in Science Teaching, 49(9), 1181-1210. https://doi.org/10.1002/tea.21054

Horbath, J., \& Gracia, M. (2014). The Educational Assessment in Mexico. Journal of International Relations, Strategies and Security, 9(1), 59-85.

Iriani, D. H., Syahdan, -, \& Nuriadi, -. (2018). The effect of early English learning on psychology. International Journal of Social Sciences and Humanities, 2(1), 65-74. https://doi.org/10.29332/ijssh.v2n1.82

Larry, M. y. (2009). Statistic 4th Edition. Em M. R. Stephens, Statistics 4th Edition (pp. 5 - 601). Mexico: Mc Graw-Hill.

Lopez, B. (2005). Learning assessment.Mexico: Editorial Trillas.

Lopéz, V., Martinez, L., \& Julian, J. (2008). The Formative Assessment Network, University Teaching. Journal of University Teaching, 2, 2-19. https://revistas.um.es/redu/article/view/3381/3281

Macías, E. I. P., Cedeño, H. A. C., \& Chávez, G. M. R. (2018). Importance of Improving Resilience in TeachingLearning Process of Students with Disabilities. International Research Journal of Management, IT and Social Sciences, 5(2), 120-128.

Mahendra, I. W. E. (2016). Contextual learning approach and performance assessment in mathematics learning. International Research Journal of Management, IT and Social Sciences, 3(3), 7-15.

Martin. (2007). Formative assessment and its repercussion in the classroom climate. Educational Research, $389-402$.

Martinez, R. F. (2013). Difilcultades to implement formative evaluation: Literature Review. Educational Profiles, 35(139),128-150.

McMillan, J. H. (2001). Secondary teachers' classroom assessment and grading practices. Educational Measurement: Issues and Practice, 20(1), 20-32. https://doi.org/10.1111/j.1745-3992.2001.tb00055.x

Mora, A. (2004). Educational assessment: Concepts, periods and methods. Research News in Education, 3-4. Fonte: https://www.redalyc.org/pdf/447/44740211.pdf

Stiggins, R. (2007). Assessment for learning: An essential foundation of productive instruction. Ahead of the curve: The power of assessment to transform teaching and learning, 59-76.

Stufflebeam, D., \& Shinkfield, A. (2015). Systematic evaluation.Spain: Ediciones Paidós Ibérica.

Suryasa, I. W., Prayoga, I. G. P. A., \& Werdistira, I. W. A. (2017). An analysis of students motivation toward English learning as second language among students in Pritchard English academy (PEACE). International Journal of Social Sciences and Humanities, 1(2), 43-50. https://doi.org/10.29332/ijssh.v1n2.36

Talanquer, V. (2015). La importancia de la evaluación formativa. Educación química, 26(3), 177-179. https://doi.org/10.1016/j.eq.2015.05.001

Zubieta, T. \&. (2017). Evaluation in the learning process. PSINTS, 15 - 30. 


\section{Biography of Authors}

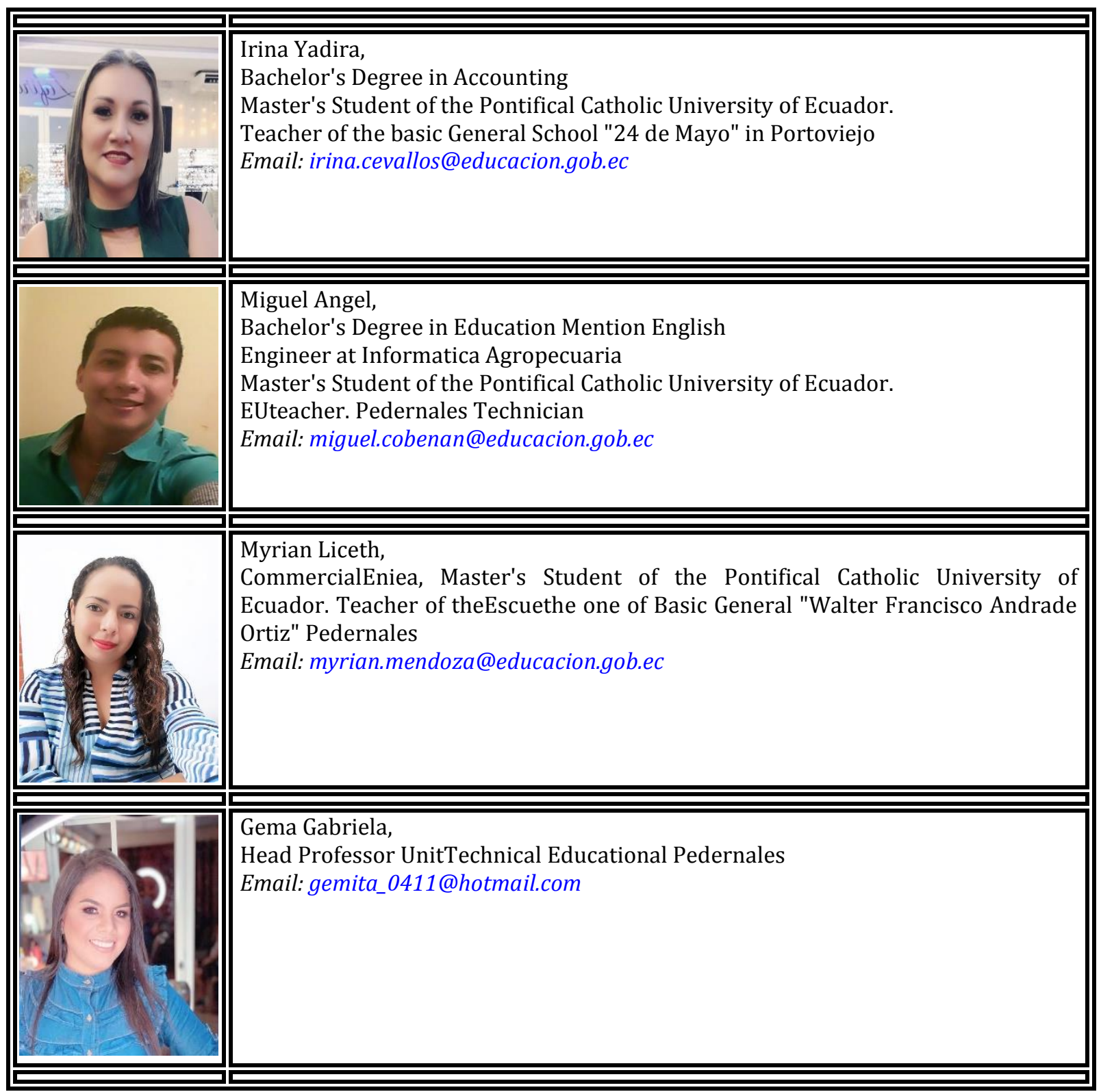

Menéndez, I. Y. C., Napa, M. A. C., Moreira, M. L. M., \& Zambrano, G. G. V. (2019). The importance of formative assessment in the learning teaching process. International Journal of Social Sciences and Humanities, 3(2), 238249. https://doi.org/10.29332/ijssh.v3n2.322 